\section{Sustaining Digital Technology Use in Professional Communities}

\author{
Angela Siew-Hoong Lee ${ }^{1}$ and Don Passey ${ }^{2}$ \\ ${ }^{1}$ School of Science and Technology, \\ Department of Computing and Information \\ Systems, Sunway University, \\ Bandar Sunway, Selangor, Malaysia \\ ${ }^{2}$ Centre for Technology Enhanced Learning, \\ Department of Educational Research, \\ Lancaster University, Lancaster, UK
}

\section{Synonyms}

Adapting to new software and hardware; Learning and training with digital technologies; Long-term digital practice; Professional development; Sustaining change and adaptation; Using digital technologies

\section{Introduction}

The progression and evolution of information and communication technologies (ICT) has brought about large amounts of change structure-wise, including trade expansion, economic, and even concepts of globalization. Access through ICT has led to the enhancement of the availability of information. Looking back to the late 1990s, the Internet was just becoming available and mostly existed on university campuses or for the military. After a decade, Internet access and other technologies were seen more widely, and now many people have access to them.

In the last few years, it is undeniable that individuals, schools, colleges, and companies are spending more money and resources on technologies. However, there seems to be a lack of ongoing information about peoples' perceptions towards digital technologies, and how these might affect organizational structures or practices. This article explores this issue, with how individuals sustain their uses of digital technologies over long-term periods; it will consider a case of Malaysian individuals' perceptions of uses of digital technologies, how change and adaptations are being sustained, compared to those in the United Kingdom (UK). It will explore drivers that contribute to how individuals adapt to ongoing changes that are happening in the technological world, and based on current research, offers a model for future development of sustained practice.

\section{Background}

Businesses are creating and capturing value, using ways of interacting and communicating, benefiting from where and how people are working, all arising from and due to the influence and changes of technology in the global world that ICT supports and enables (Cascio and Montaelegre 2016). 
Big data and machine learning, advanced robotics and drones, cloud and mobile computing, and technologies that are clean-energy are technologies which are currently at the emerging edge, transforming and driving the starting points of some businesses globally.

However, evidence from studies undertaken over the past 20 years or more (e.g., Gao et al. 2011; OECD 2015; Tatnall and Davey 2014) shows a repeated lack of long-term uses of digital technologies by teachers, trainers, and employees to support what would be regarded as effective enactment, for their teaching, training, or workbased practices. While studies have identified drivers and barriers (e.g., Conole 2016; Porter and Graham 2016), studies exploring reasons for long-term sustained uses have not emerged as frequently (e.g., Mumtaz 2000). Developing effective practitioner enactment (Heitink et al. 2016; Khan et al. 2016) requires detailed knowledge about relationships of factors and features that enable teachers, trainers, and employees to understand how and why they can use digital technologies in their respective work areas. Features and factors enabling use not only concern professional attitudes and understanding of technological affordances and facilities but also attitudes and understanding towards technologies and, importantly, innovation. If appropriate learning, teaching, training and work-based uses are to develop over periods of time, rather than being restricted to the short-term, to accommodate rapid technological changes, then enactment should be concerned not just with pilot and project-based uses, but with long-term interactions where adaptation and change facility are inherent to professional practice.

Factors that can affect an individual's attitude towards any kind of new technology might be their age, gender, or even their peers' attitudes and perceptions. There are challenges when introducing new technologies, such as achieving user acceptance, but at the same time, organizations are also trying to retain levels of acceptance when it comes to performance and productivity (Ahmad 2014). Reasons why companies or organizations are introducing new technologies can be to increase quality and productivity, to reduce costs and dependence on skilled labor, to be up-to- date, to retain their position when competitors also introduce new technologies, and to change relations and interactions among various groups within organizations (Dawson 2007). In many businesses and organizations (including those that are educationally focused), there is an increase of participation among employees who are remote or faraway. Technologies can assist and expand the number of employees who are collaborating or working together with technology tools such as the Internet, shared databases, and internal intranets. Regardless of location (accepting Internet accessibility), technology enables sharing challenges that are faced by remote employees to be overcome (Schraeder et al. 2006).

The most unavoidable factor in the business world is change. It is important for an organization's toolset to be upgraded on a regular basis, and furthermore, their employees and staff need to accept changes applied. Changing employee and staff perceptions and behaviors cannot be done and forced overnight; it is a long-term objective, a critical factor being the provision to the employees of the full context of the changes, as this will allow them to understand the need for such changes (Croft and Cochrane 2005). When it comes to organizations, it is the role of managers to provide justifications, reasons, and rationales as to why it is necessary to make these changes in order to create a degree of readiness, as this will increase the likelihood for the employees to accept and participate in the changes applied (Ford et al. 2008). Furthermore, managers play a very important vital role in coordinating, controlling, and leading employees within their businesses, to ensure that any technologies that are integrated into use are technologically fit for the purposes of the organization (Kao et al. 1996).

A factor that can influence a manager's performance is, firstly, training. Training and sufficient guidance should be provided to employees on how to use new technologies if the technologies will be an essential tool for the business, and such professional technological training needs to be taken seriously, with an appropriate transition flow (Alan 2010). This should be considered and viewed as a vital investment (Reese and Porter 2008). A further factor for managers to consider 
is modern technology's mobility. What most managers look for are tools that enable them to do their tasks at any given time and even for them to bring their work home or their abilities to complete it in any location beyond the office. Mobility of the technology helps in increasing profitability and also productivity (Pfano and Beharry 2016). Usefulness, when it comes to office technology, is a factor; and technologies that are indeed useful may well be used every day (Billhilf 2006).

In order to implement a technology change successfully, areas that need to be addressed effectively include any internal conflict challenges or resistance by employees, adequate consideration and planning of an employee's training, multigenerational workforce concerns, and communication. All of these can be addressed, involving an implementation plan that is adequately conceived, a training plan that is feasible and potentially effective and, lastly, when it comes to communication between management and employees, there must be open communication (Delaney and D'Agostino 2015).

In this digital era, the use of computers has become easier, offering benefits that arise from new functionality. It is undeniable that all areas of production in many organizations have been transformed by the computer (McConnell 1996). Many organizations are devoting their resources so that their employees are gaining substantial training, as training is seen as a "must" to keep oneself updated. The University of Virginia, for example, is constantly providing computer training for their staff (some two to three thousand in number) with workshops that have involved total participant numbers up to 2000 for the last 4 years. The training hours total about 3.86 per employee per year (Friedberg 2003). Subsequently, organizations are showing benefits as a result; one organization that spent a great deal on purchasing a large number of computers showed a greater reciprocity when it comes to skilled labor (Eric and Loren 1997; Lehr and Lichtenberg 1998). Since the 1990s, there has been an increasing awareness regarding on-the-job training as the most appropriate method of educating and teaching employees necessary skills (Jacobs and Jones 1995). Furthermore, support from peers and supervisory personnel are variables that have contributed to the effectiveness of training programs (Bates et al. 2000).

On-demand businesses are now combining technology with information technology, so that these companies can be profitable, responsible, and rapid. Today, enterprise considers flexibility as a key factor. Flexibility in this sense is concerned with adaptability when responding to any kinds of new demands in the current market and taking whatever opportunity may come along (Tohidi 2011). User satisfaction with using technology is undeniably important. What contributes towards how well any resources are being utilized in an individual's work life depends on their aptitude, ability, attitude, and even beliefs about information technology (Venkatesh 1999).

\section{Cases in Malaysia and the UK}

An example study which illustrates key points about sustainability of digital technology practices, conducted in the UK and Malaysia (Passey and Lee 2018), gathered qualitative data about individual approaches to sustaining uses of digital technologies for learning, teaching, and training. Interviewed participants had used technologies in their careers for learning, teaching, and training purposes for many years. The study gathered evidence about:

1. How long the participants had been using technology devices to support learning, training, or employment.

2. Over that time, what hardware changes they had encountered, and which devices they had used at different times over that period.

3. The software changes they had encountered over that time, which software they had used, and when they started to use these.

4. What their experiences were in terms of performance when they started to use new hardware and software - for example, whether it went down, stayed the same, or 
Sustaining Digital Technology Use in Professional Communities, Table 1 Genders of the participants interviewed

\begin{tabular}{l|c|l|l}
\hline Gender & UK & Malaysia & \\
\hline Women & 6 & 4 & 10 \\
\hline Men & 8 & 12 & 20 \\
\hline Total & 14 & 16 & 30 \\
\hline
\end{tabular}

went up and how long these sorts of shifts in performance lasted.

5. The benefits they experienced from uses, whether these were what they would regard as the most important benefits, and whether these shifted at all over time.

6. How they managed to maintain uses of technologies when software or hardware changed, and what they did so that they could use the new or updated software or hardware.

7. Whether there were other people around them, in their situations or context, which made a difference in this respect, and if so, whether they would say those differences were positive or negative.

8. Whether there were particular contextual factors that had been important in helping them to adapt to new technologies at certain times. For example, whether they would rate any of the following as being important to sustaining their enactment in the school, college, university, or work:

(a) A shared vision of technological uses

(b) Empowerment from leaders

(c) Implementation planning

(d) Consistent and adequate funding, either personally or from the institution

(e) Equitable access, compared to others

(f) Ongoing professional development

(g) Technical support

(h) A framework of how to use the technologies in the institutional curriculum or work plan

(i) The ability to choose when to use the technologies

(j) Assessment and evaluation of their practices using technologies

(k) Engaged communities of users

(l) A supportive external context at home or outside the institution
9. Whether any of these factors, or others, hindered their ability to adapt to technology changes over time.

10. How they considered the value of uses of technology overall - for example, as a requirement, or something that is useful, as a tool, an add-on, something about which they need to be kept informed for their learning, training, or work.

11. Whether they thought it was important to maintain contact with and integrate technology with their learning, training, or work, and if so, why they thought that was so.

12. What they thought the main personal factors or characteristics were that enabled them to adapt to technology changes over time.

A total of 16 respondents from Malaysia and 14 in the UK participated in the studies. Most were men (20 compared to 10 women), as shown in Table 1.

From Table 2, it can be seen that most of the respondents in the study coming from Malaysia were between the ages of 21 and 40 years (a younger adult group), whereas the respondents in the UK were mostly aged between 41 and 60 years (a middle-range age group).

Table 3 shows that most of the interviewees had been using technologies for 10-20 years in Malaysia, while in the UK most had been using technology for longer time periods, for 21 years or more. Compared to the UK, participants in Malaysia had used technology for shorter periods of time.

\section{Experiences of Long-Term Sustained Users of Digital Technologies}

When asked about their experiences with hardware changes over the times they had been 


\section{Sustaining Digital Technology Use in Professional \\ Communities,}

Table 2 Age ranges of interviewees

\begin{tabular}{l|l|l|r}
\hline Age band & Malaysia & UK & \\
\hline Between 21 and 40 years of age & 14 & 2 & 16 \\
\hline Between 41 and 60 years of age & 2 & 11 & 13 \\
\hline 61 years of age and above & 0 & 1 & 1 \\
\hline Total & 16 & 14 & 30 \\
\hline
\end{tabular}

Sustaining Digital Technology Use in Professional Communities, Table 3 How long technologies had been used by the interviewees

\begin{tabular}{l|l|l|r}
\hline How long technologies have been used & Malaysia & UK & \\
\hline For up to 10 years & 9 & 1 & 10 \\
\hline Between 11 and 20 years & 7 & 3 & 10 \\
\hline Between 21 and 30 years & 0 & 6 & 6 \\
\hline 31 years and over & 0 & 4 & 4 \\
\hline Total & 16 & 14 & 30 \\
\hline
\end{tabular}

using the technologies, and what kinds of devices they had used over that period, most Malaysian participants stated they had used laptops (8 respondents), tablets (3 respondents), CD-ROM (Compact Disk Read Only Memory)/ floppy disks (3 respondents), mobile telephones ( 7 respondents), monitors (5 respondents), thumb drives/external hard-disk drives (3 respondents), and mobile technologies (2 respondents). Some also identified the Internet, Microsoft (MS) Windows, televisions, sensor devices, gaming devices, digital audio recorders, the iCloud all system, telephone cables, printers, keyboards, mice, and Wi-Fi that they had used before as time went on. Compared to the UK study (Passey and Lee 2018), respondents in the UK related hardware changes they encountered based on periods of their life such as their childhood, their first job, etc.

When asked about software changes, Malaysian respondents clearly recognized changes when they moved from one software to another such as Microsoft (MS) in general (5 respondents), MS Word (3 respondents), MS PowerPoint (3 respondents) and MS Excel (2 respondents), and 9 respondents recognized the changes more when it came to using Adobe software like Illustrator and Photoshop. Other software changes identified were related to more specific packages, the iPhone Operating System (iOS), virtual private networks (VPNs), Oracle, computer languages such as Turbo Pascal, visual basic (VB), Java, standardized query language (SQL), SAS Visual Analytics, Webex, Shem's Risk Management System (SRMS), fourth generation language (4th GL), computer-aided design (CAD), X-Mind, and Figma Sublime software. Respondents from the UK did not relate software changes to periods of times when they used them, instead identifying the changes of software in a more general way, concerned with features and functionality of the software. This difference between the respondent groups might be related to the different lengths of times that the respondents in the two countries had used technologies.

When interviewees in Malaysia were asked about their experiences in terms of performance of new hardware or software, most respondents agreed that performance had increased significantly (6 respondents) and also they noted productivity increases too (4 respondents). Some agreed that technologies had become more userfriendly ( 3 respondents), loading time was faster ( 2 respondents), their learning improved the more they used it (1 respondent), it was more consistent (1 respondent), and hardware had got better (1 respondent). A few participants thought technology performance had stayed the same, or it 
Sustaining Digital Technology Use in Professional Communities, Table 4 Contextual factors influential in maintaining sustained uses of technologies over time

\begin{tabular}{|c|c|c|c|c|}
\hline Contextual factor & $\begin{array}{l}\text { UK } \\
\text { Yes }\end{array}$ & $\begin{array}{l}\text { UK } \\
\text { No }\end{array}$ & $\begin{array}{l}\text { Malaysia } \\
\text { Yes }\end{array}$ & $\begin{array}{l}\text { Malaysia } \\
\text { No }\end{array}$ \\
\hline 1. A shared vision of technological uses & 11 & 3 & 14 & 2 \\
\hline 2. Empowerment from leaders & 12 & 2 & 14 & 2 \\
\hline 3. Implementation planning & 14 & 0 & 15 & 1 \\
\hline 4. Consistent and adequate funding, either personally or from your institution & 12 & 2 & 14 & 2 \\
\hline 5. Equitable access compared to others & 8 & 6 & 14 & 1 \\
\hline 6. Ongoing professional development & 9 & 5 & 14 & 2 \\
\hline 7. Technical support & 6 & 8 & 14 & 2 \\
\hline $\begin{array}{l}\text { 8. A framework of how to use the technologies in your institution's curriculum } \\
\text { or work plan }\end{array}$ & 11 & 3 & 14 & 2 \\
\hline 9. The ability for you to choose when to use the technologies & 7 & 6 & 12 & 4 \\
\hline 10. Assessment and evaluation of your practices using technologies & 10 & 4 & 14 & 2 \\
\hline 11. Engaged communities of users & 11 & 2 & 15 & 1 \\
\hline 12. Supportive external at home or outside your institution & 10 & 4 & 13 & 3 \\
\hline
\end{tabular}

took some time to adapt to it, or some trends did not fit their preferences. In the UK, respondents referred to more specific categories of performance of the new hardware and software in terms of increased efficiency, enhanced access, improved performance, and enhanced ease of use.

Interviewees were also asked about the benefits they had experienced from the use of technologies. Most in Malaysia said it definitely improved their productivity ( 7 respondents), it also saved time (3 respondents), and helped them to communicate and work more easily (3 respondents). Other benefits mentioned were increased convenience, efficiency, gaining more security, and greater experience and basic knowledge of using the software over time. This pattern was similar to that recognized by the UK respondents.

Regarding the question of how they managed to maintain their uses and address challenges of changing technologies and what they did in order to use the updated software or hardware, most Malaysian respondents said that they sought help online either through a tutorial/ guide/wikiHow/forum (8 respondents), YouTube (3 respondents), or Google (2 respondents). Five respondents said they taught themselves how to use the software, while two respondents went on many courses or read books and just updated on the basis that was needed. Three respondents asked somebody else or just tried it out themselves, and one respondent said they tested before updating or just went on a training course when the programs were much more sophisticated. The UK participants related similar responses, but, perhaps related to their age profile or not, the way they resolved their challenges was by talking to people who were "IT savvy" which they said "helped them a lot." They were also influenced by their children's uses of technology, including using technologies that enabled them to communicate with their children. Additionally, they said that support units in their places of work or employment, such as IT support, helped them too.

Table 4 shows interviewee responses regarding questions about particular contextual factors that they regarded as being important in helping them to adapt to new technology. All of the contextual factor specified were important to many respondents, but those highlighted especially were implementation planning (29 responses in total) and engaging communities of users (26 responses). The least commonly highlighted was the ability for them to choose when to use the technologies (19 responses). It is clear that respondents rely upon a variety of supportive factors, rather than any specific factor or group of these. 
From the details within Table 4, it is clear that the shared vision of technological uses, empowerment from leaders, implementation of planning, consistent and adequate funding from the institution, a framework of how to use the technologies in their institution's curriculum or work plan, and engaging communities of users showed similar high response rates for both countries. The majority of respondents agreed that these factors were key in influencing them on sustaining the use of technologies over time. The responses of Malaysian and UK participants were different when it came to accessibility of the technologies, technical support, and professional development. The younger age range adults from Malaysia said more commonly that the factors of accessing technologies when they chose to, and to seek support easily were important, whereas a lower proportion of the middle aged group from the UK indicated the importance of factors concerned with when to use the technologies and to access technical support.

When asked if the factors mentioned had hindered their ability to adapt to technology changes over time, some indicated that this was the case. While some indicated hindering reasons like limited funding, only one respondent indicated that implementation planning was a hindering factor.

Interviewees were asked how they considered the use of technology overall. Some respondents in Malaysia said that it was essential and necessary to their work (4 respondents). Two respondents stated each of following: as a requirement to adapt to new technology, or something that is useful; or as a tool, an add-on, or something that you need to keep involved in with how you learn, train or work. Other participants stated that technologies are needed to maintain today's standards, to evolve, to keep up with changes of technology, as a vital tool, making sure technology can be used, but to make sure that it is fully utilized, to engage students, or help customers to meet their requirements, including uses for communication. In the UK, responses generally indicated the essential value of technologies, to support and enhance productivity and communication.
Participants were asked if it was important to maintain contact with and integrate technology with learning, training, or work. Many participants in Malaysia agreed that it was important (12 respondents). The reasons given for this were to use technology to appropriately encounter obstacles that it is easier to stay connected, to solve problems immediately, to stay up-to-date in the IT industry, that the world is growing and so technology is surrounding us, and to make sure that we are updated with technological enhancement. A similar pattern of responses was gained from the UK participants, who indicated that changes in technologies were providing positive enhancements for addressing issues and challenges but that these might need to be explored by the individual within their specific contexts.

When participants in Malaysia were asked what they thought were the main personal factors or characteristics that had enabled them to adapt to technology changes over time, many of them said self-exploration (3 respondents), being humble and willing to learn things (3 respondents), personal interest ( 2 respondents), and curiosity of new technology ( 2 respondents). Others indicated the need for a positive attitude towards technology, enjoying learning, having an inquisitive nature, having a passion with gadgets, confidence, being positively responsive to change, and being sensitive to what is out there. The UK participants responded similarly, but highlighted key characteristics such as inquisitiveness and having a positive attitude towards technology.

It was clear from both sets of respondents that personal factors or characteristics were vitally important in enabling individuals to maintain their interest in and abilities to accommodate change with technologies over time. The role of personal characteristics and attitudes is shown across these samples of long-term users to be significant; the role of technical training is stated far less. Rather, it is access to individuals or resources that can support technical training that is reported as being more important than the technical training per se. 


\section{Factors that Contribute to Sustained Uses}

Based on previous research literature and on the analysis from this case, it is shown that participants who have been involved in longterm use of technologies to support their learning, teaching, training, and work-based practices are finding ways to accommodate to change in technologies. With regard to using previous hardware and devices, individuals may recognize that they had noticed changes with the introduction of certain technologies - mobile technologies, tablets, laptops, floppy disks, CD-ROMs, and thumb drives. In terms of software changes, it appears to depend on the specific forms of software that individuals need to use and choose to use, but individuals may recognize changes in software that have been available over quite long periods of time, such as Microsoft and Adobe products, as well as more specific software applications that are used for specific purposes. Reasons for noticing these changes may well be related to advancements in the technologies that have brought significant benefits, as those who sustain uses highlight increases such as those in performance and communication, and greater consistency in hardware, leading to improvements in productivity due to increased speed and loading time, with less waiting time involved. Regular software updates are noted to introduce friendlier user interfaces leading to greater overall usability. Importantly, "practice makes perfect" can be an overall concern of long-term users - by consistently exploring, accommodating beneficial affordances, and using software; over time, this leads to its becoming easier to use. The introduction of smartphones, tablets, and laptops can be noted to enable access and work to be done anywhere and anytime, leading in many cases to increased convenience, efficiency, and productivity. However, the dependence on technologies and the need to respond anytime and anywhere can be seen by some as an issue that needs to be considered and managed carefully, to ensure that personal time is not invaded inappropriately.

To enhance the learning of new facilities in technologies, materials and sources on the
Internet are increasingly mentioned as a preferred choice, with many tutorials online which can help. Some long-term users indicate that they prefer to do things on a trial and error basis, while others prefer to refer to more documentation. With the need to use and apply new hardware or software to an individual's context, a single approach may be adopted by an individual, but a variety of approaches are likely to be taken across a population.

Technological advancements have not only provided an increase in productivity, performance, efficiency, or convenience in work and jobs but they have been recognized by long-term users as creating a platform for communication across individuals. Some significant responses highlight benefits, such as the positivity of technology advancements which helped a single child deal with loneliness, as well as how older generations are accepting technological changes that can be an inspiration to others. In some cultural contexts, such as that in Malaysia, if younger people see their parents or older generations using smartphones and tablets with ease, it is felt that this may well trigger a common topic of conversation, where people would talk about how "even the older generations are attracted to the use of these technologies."

In terms of particular contextual factors being important in helping individuals adapt to new technologies, evidence has shown that through adequate engagement and empowerment, planning, adequate resources, technical support, and the ability to choose which technology to use, such factors are influential in mainlining the sustainability of uses of technologies.

The evidence that personal characteristics, which are consistently related by individuals who develop practices and uses of technologies over long-time periods, is of particular note. Characteristics such as self-exploration, a willingness to learn new things, personal interest, having a positive attitude towards technology, having an inquisitive nature, and being sensitive to what is out there and what is possible, are all key factors that individuals rely upon to develop uses to suit their needs. This focus on the personal characteristics has been somewhat 
underplayed by the support community, yet is clearly an important area for future concern.

The integration of technologies with learning, training, and work has been deemed to be important, as it allows individuals to solve problems, to act as a communication tool and to provide individuals with the means to stay updated. While technologies have increased productivity, efficiency, speed, and performance as well as provided people with a platform of convenience, it is clear that this has arisen as a consequence of their personal interest, drive, and inquisitive concerns.

\section{Approaching the Development of Sustained Uses of Digital Technologies}

In conclusion, research studies have provided an overview to show that individuals who continue to use technologies for long periods of time are accommodating and accepting of technological advancements and changes. More importantly, the drive behind the acceptance of change is due to a willingness to learn, a sense of curiosity, and a positive attitude towards technology. Thus, sustainability of uses of technologies in communities seems to suggest a positive future in this respect where positive attitudes are positively supported. It is not so much a matter of whether it is a choice for people to accept but is more about adaptability and willingness to accept these technology changes and to explore how they can be of value. In countries studied, individuals with long-term use have learnt to understand the potential and importance of technology, how it can and has benefited their daily lives (whether for personal or work purposes), and how, due to emerging technologies, it has enhanced their lives.

A proposed model for future development of sustained effective and innovative uses of technologies is offered in Fig. 1 (from Passey and Lee 2018). Features of this model relate to factors for successful professional development identified earlier by Joyce and Showers (2002): persistence; acknowledgement of the transfer problem; teaching new behaviors; understanding the importance of the underlying theory; proactive and productive use of peers; and flexibility. Evidence from current studies confirms a continued need to focus on these affective, as well as technological, content, and pedagogic factors.

Research findings suggest that institutions that have focused on providing technical support alone should rethink their positions. Rather than a single focus on technical support and affordances,

\section{Sustaining Digital Technology Use in Professional Communities,}

Fig. 1 Proposed model for future development of sustained effective uses of technologies. (Source: Passey and Lee 2018)

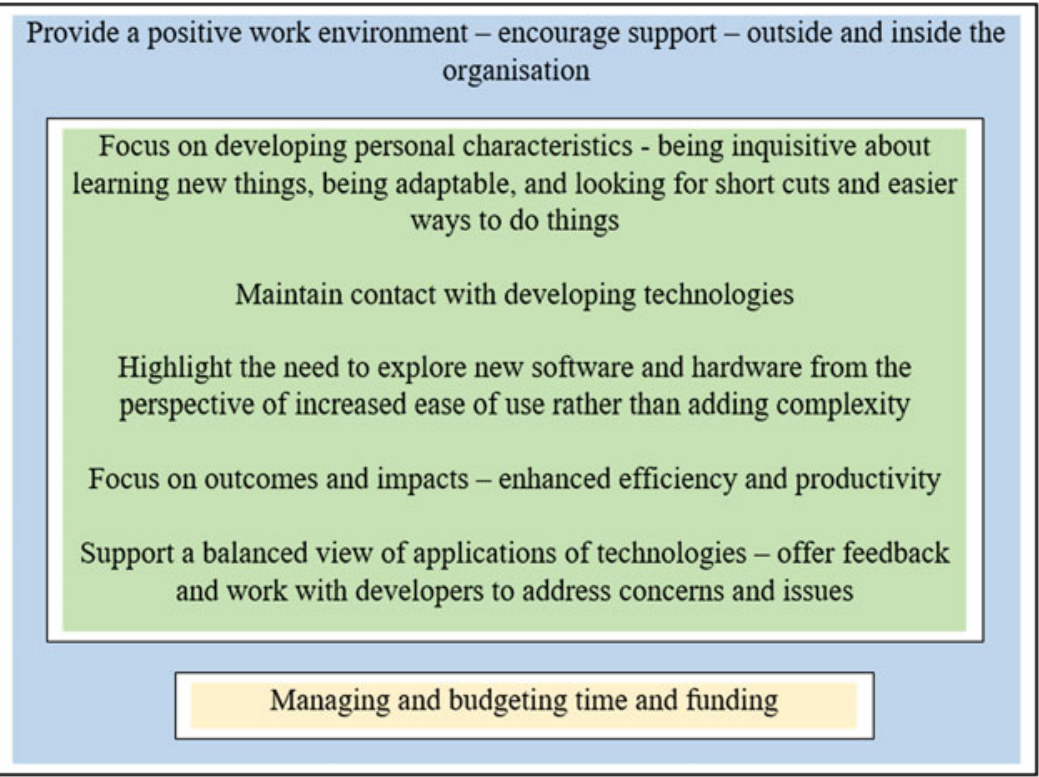


evidence indicates that institutions should focus on developing personal characteristics concerned with enquiry and inquisitiveness, highlighting outcome and impact support. This suggests moving away from technical support that focuses on affordances alone, to a focus on outcome and impact support. While there is a clear continued need for essential technical maintenance and implementation to interface with institutional foundations, ensuring infrastructure and accessibility, outcome and impact support for users from a developing personal characteristics perspective is vitally important. It is clear that some support in some institutions is provided in this way, with a distinction being made between infrastructure and network support, and user interface support. However, evidence argues for a focus of user interface support to be on developing creative and innovative personal characteristics that can be applied to technologies. There is clearly a need for institutions and individuals to consider the growing importance of developing digital agency at a personal level (Passey et al. 2018).

\section{Cross-References}

- Different Methodological Approaches to Considering the Adoption of ICT

- Situative Perspective and Determinants of Technology Acceptance in Educational Technology

- Teacher Education and Professional Development for Technology Integrated Teaching

- Teacher Education, Thinking About ICT

\section{References}

Ahmad S (2014) Technology in organizations. Int J Res Bus Manag 2(7):73-80

Alan D (2010) The hidden value of technical training. http://eval.symantec.com/mktginfo/enterprise/articles/ bciodigest_apr10_solutions_education.en-us.pdf. Accessed 27 May 2012

Bates RA, Holton EF III, Seyler DL, Carvalho MA (2000) The role of interpersonal factors in the application of computer-based training in an industrial setting. Hum Resour Dev Int 3(1):19-42
Billhilf (2006) The 15 most useful technologies in 2006. http://blogs.technet.com/b/port25/archive/2006/12/11/ the-15-most-useful-technologies-for-me-in-2006.aspx. Accessed 15 Aug 2012

Cascio WF, Montaelegre R (2016) How technology is changing work and organizations. https://doi.org/ 10.1146/annurev-orgpsych-041015-062352

Conole G (2016) MOOCs as disruptive technologies: strategies for enhancing the learner experience and quality of MOOCs. Rev Educ Distancia 50(2). https:// doi.org/10.6018/red/50/2

Croft L, Cochrane N (2005) Communicating change effectively. Manag Serv 49(1):18-33

Dawson B (2007) The impact of technology insertions on organizations. Human Factors Integration Defence Technology Centre. University of Birmingham, Birmingham, UK. Retrieved on 15 Dec 2013 from http:// www.hfidtc.com/research/process/reports/phase-2/ HFIDTC-2-12-2-1-1-tech-organisation.pdf

Delaney R, D'Agostino R (2015) The challenges of integrating new technology into an organization. Math Comput Sci Capstones 25

Eric B, Loren H (1997) Computing productivity: are computers pulling their weight? Sloan School of Management, Massachusetts Institute of Technology, Cambridge, MA

Ford JD, Ford LW, D'Amelio A (2008) Resistance to change: the rest of the story. Acad Manag Rev 33(2):362-377

Friedberg L (2003) The impact of technological change on older workers: evidence from data on computer use. ILR Rev 56:511

Gao P, Wong AF, Choy D, Wu J (2011) Beginning teachers' understanding performances of technology integration. Asia Pac J Educ 31:211-223

Heitink M, Voogt J, Verplanken L, Braak JV, Fisser P (2016) Teachers' professional reasoning about their pedagogical use of technology. Comput Educ 101:70-83

Jacobs RL, Jones MJ (1995) Structured on-the-jobtraining: unleashing employee expertise in the workplace. Berrett-Koehler Publishers, San Francisco

Joyce B, Showers B (2002) Student achievement through staff development. National College for School Leadership, Nottingham

Kao S, Kuo L, Chen LH, Wang TY (1996) Improving productivity via technology and management. Int J Syst Sci 27(3):315-322

Khan MSH, Bibi S, Hasan M (2016) Australian technical teachers' experience of technology integration in teaching. SAGE Open 6(3):1-12

Lehr B, Lichtenberg F (1998) Computer use and productivity growth in federal governments agencies, 1987-92. J Ind Econ 46(2):257-279

McConnell S (1996) The role of computers in reshaping the work force. Mon Labor Rev 119(8):3-5

Mumtaz S (2000) Factors affecting teachers' use of information and communications technology: a review 
of the literature. $\mathrm{J}$ Inf Technol Teach Educ 9(3):319-342

OECD (2015) Students, computers, and learning: making the connection. OECD, Paris

Passey D, Lee A (2018) Planning future professional development: Effecting innovative approaches to practice. Paper presented at the 2nd International Conference on Entrepreneurship, Innovation and Leadership (ICEIL-2018), Uttar Pradesh, India

Passey D, Shonfeld M, Appleby L, Judge M, Saito T, Smits A (2018) Digital agency - empowering equity in and through education. Technol Knowl Learn 23(3):425-439. https://doi.org/10.1007/s10758-018-9 384-X

Pfano M, Beharry A (2016) The effect of modern office technology on management performance: Durban Westville. Probl Perspect Manag 14(2-2):376-384
Porter WW, Graham CR (2016) Institutional drivers and barriers to faculty adoption of blended learning in higher education. Br J Educ Technol 47(4):748-762

Reese WD, Porter C (2008) Skills of management. Cengage Learning, London

Schraeder M, Swamidass PM, Morrison R (2006) Employee involvement, attitudes and reactions to technology changes. J Leadersh Org Stud 12(3):85

Tatnall A, Davey B (eds) (2014) Reflections on the history of computers in education: using computers and teaching about computing in schools from the late 1970s to the early 1990s. Springer, Heidelberg

Tohidi H (2011) Modelling of business services in service oriented enterprises. Proc Comput Sci 3:1147-1156

Venkatesh V (1999) Creation of favourable user perceptions: exploring the role of intrinsic motivation. MIS Q 23(2):21-43 